\title{
Clinical applications of neuroimaging in patients with Alzheimer's disease: a review from the Fourth Canadian Consensus Conference on the Diagnosis and Treatment of Dementia 2012
}

Jean-Paul Soucy ${ }^{* 1}$, Robert Bartha ${ }^{2}$, Christian Bocti ${ }^{3}$, Michael Borrie ${ }^{4}$, Amer M Burhan ${ }^{4}$, Robert Laforce $\mathrm{Jr}^{5}$ and Pedro Rosa-Neto ${ }^{6}$

\begin{abstract}
In May 2012, the Fourth Canadian Consensus Conference on the Diagnosis and Treatment of Dementia brought together in Montreal experts from around Canada to update Canadian recommendations for the diagnosis and management of patients with neurodegenerative conditions associated with deterioration of cognition. Multiple topics were discussed. The present paper is a highly condensed version of those recommendations that were produced to support discussions in the field of neuroimaging for clinical diagnosis of those conditions.
\end{abstract}

\section{Introduction}

General considerations on the imaging group from the Fourth Canadian Consensus Conference on Diagnosis and Treatment of Dementia

Functional and structural neuroimaging in dementia was thoroughly reviewed in two papers from the last Canadian Consensus Conference on Diagnosis and Treatment of Dementia (CCCDTD) conference, published in $2007[1,2]$. The field has since grown rapidly through refinements of techniques previously discussed and through deployment of new strategies such as in vivo amyloid imaging. This article, a much abridged version of the thorough review papers prepared for discussion at the CCCDTD4 conference, covers the most significant of those developments. The original articles can be found online [3].

*Correspondence: jean-paul.soucy@mcgill.ca

'PET Unit, McConnell Brain Imaging Centre, Montreal Neurological Institute, McGill University, 3801 University Street, Montreal, Quebec, Canada H3A 2B4

Full list of author information is available at the end of the article
The primary goal of the CCCDTD meetings is to elaborate practical recommendations for Canadian clinicians dealing with patients presenting with cognitive impairment. Other groups have of course come up with such recommendations. However, the present paper differs from those others in many ways. First, this paper certainly has the advantage of having reviewed a literature that is more recent (in a field in rapid flux) than that on which publications from the previous CCCDTD meetings were based, as well as those from organizations such as the American Academy of Neurology [4], the UK National Institute for Health and Clinical Excellence [5] or the European Federation of Neurological Societies [6]. The paper also had access to the most recent effort of the same nature, from the National Institute on AgingAlzheimer's Association [7,8], which is tailored to a very different medical practice environment.

The CCCDTD4 conference was attended by a group of individuals selected based on their known clinical expertise as decided by the conference organizers, who themselves are pre-eminent Canadian experts in the field of dementia, and who also organized previous meetings in that series. For the imaging section, a mix of imagers and clinicians, as well as basic scientists, were tasked with the preparation of the document to be discussed. The general attendance at the conference also included clinicians from the specialized (neurologists, geriatricians) and general medicine communities, physicians with expertise in methodological evaluation, as well as people representing the public and the pharmaceutical industry (those latter two groups did not take part in the voting for approval/rejection of recommendations).

The search of the literature for this specific paper was based on PubMed, and covered the period from the last CCCDTD publication (CCCDTD3, January 2006) until January 2012, so as not to duplicate the reviews already performed in the previous meetings. The current work is 
not a meta-analysis and therefore the search was not defined by statistical parameters, but rather by a series of decisions by the authors to include papers or not based on the pertinence of the information they contain. In fact, this resulted in some selected papers being included from the period preceding the interval mentioned above, if they were deemed necessary for a better understanding of the recommendations being made.

Keyword sequences started with 'Alzheimer 's disease' (AD) or 'mild cognitive impairment' (MCI), and then added the modalities being covered ('X-ray computerized tomography' (CT), 'CT', 'head CT', 'magnetic resonance imaging' (MRI), 'MRI', 'PET-FDG', 'SPECT-blood flow', and so forth). 'ADNI' was also used as a search term because articles related to that project constitute a rather unique sample of data analysis papers on well-characterized cases that have generally been submitted to multiple diagnostic modalities.

The official recommendations from the CCCDTD4 meeting for clinical use of neuroimaging in patients with cognitive decline can be found in Table 1.

\section{General considerations on clinical neuroimaging in dementia}

Because the limited pharmacological therapeutic options available for patients with cognitive decline linked to neurodegenerative diseases are not, of course, universally effective across the different entities found in that population, are costly, and can have significant side effects $[9,10]$, their rational use requires high accuracy of patient classification. This classification is what any type of neuroimaging technique is ultimately used for in such populations. Moreover, precise categorization has significant implications in terms of prognosis and even counseling; for instance, frontotemporal dementias have a significant probability (up to 40\%) of occurring in a hereditary context [11], which is information many patients will value. Those reasons alone make it useful to discuss the role of neuroimaging in cases of cognitive decline.

Another important point to be considered is that neuroimaging of neurodegenerative diseases involves recognition on different types of imaging techniques of patterns deemed to be associated with a specific condition. However, neurodegenerative diseases are associated with ageing, and the probability of finding any of them in isolation in a patient decreases with increasing age [12]. Finding a pure pattern therefore becomes less and less probable as patients advance in age. Moreover, the relationship between dementia and parameters evaluated by imaging probably vary with age: amyloid load may not be as specific for cognitive impairment in very old patients as compared with younger ones, whereas indices of neuronal loss (regional volumes, metabolic activity or absolute blood flow) might show a more stable relationship to dementia across ages [13]. Brain reserve also will influence the results from those studies. Recommendations on the use of imaging techniques have to be interpreted in light of such factors, whatever the technique used. We have tried throughout the present text to make sure to take those factors into account.

\section{Structural neuroimaging - computed tomography and magnetic resonance imaging}

The search approach described above identified 416 papers on X-ray CT and MRI. A separate search using the same parameters with a filter for review articles yielded 63 papers. A search for review papers on head CT yielded only six papers.

\section{General considerations}

CCCDTD3 offered two recommendations for structural imaging pertaining to the general clinical setting [1]. On the one hand, these partially exclusionary recommendations supported the selective use of neuroimaging imaging procedures based on the First Canadian Consensus Conference on the Assessment of Dementia published in 1991 On the other hand, for the first time the recommendations supported the use of routine imaging to rulein asymptomatic cerebrovascular disease. No specific choice of imaging modality was recommended. The following is a brief review of recent evidence pertaining to the clinical use of CT scans and MRI in the assessment of cognitive impairment in older people.

\section{X-ray computerized tomography of the brain}

For the initial assessment of patients presenting with cognitive difficulties/symptoms of dementia, guidelines from several countries indicate that structural neuroimaging with CT or MRI is appropriate [4,14]. From a practical perspective, one should note that none of the guidelines differentiate between the types of technique (head CT or MRI) that should be used in the context of whether the request comes from a family physician practice or a specialist memory clinic.

One recent study found that no space-occupying lesion would have been missed in a memory clinic setting using the 1991 Canadian Consensus Criteria [15]. The study confirmed that the systematic use of neuroimaging allows for modifications of the etiological diagnosis of dementia by revealing 26 clinically unsuspected strokes among the 210 patients evaluated. The value of finding unsuspected cerebrovascular disease lies in the added benefit of managing vascular risk factors; the relevance of ordering neuroimaging is determined by the clinician's judgment as to whether aggressive vascular risk reduction is warranted in a given patient.

Space-occupying lesions, usually neoplasms or subdural hematomas, can be detected and may present 
X-ray computerized tomography and magnetic resonance imaging

- We recommend a head MRI when a radiologist/neuroradiologist and/or a cognitive specialist (neurologist, geriatrician, or geriatric psychiatrist) can interpret patterns of atrophy and other features that may provide added diagnostic and predictive value as deemed appropriate by the specialist (Grade 2B)

- Standardization of clinical acquisition of core MRI dementia sequences is recommended in Canadian centers that have radiologists and cognitive specialists with expertise in assessing cognitive disorders, particularly when repeat MRI scans can provide additional diagnostic, prognostic and safety information (Grade 2B)

- In addition to previously listed indications for structural imaging, a CT or MRI scan should be undertaken in the assessment of a person with cognitive impairment if the presence of unsuspected cerebrovascular disease would change the clinical management

- The practical message is that structural imaging is not required in all (although will be indicated in most) persons with cognitive impairment. Although more costly and less available, MRI is preferable to CT

- When available in the clinic, we recommend that cognition specialists use the computer images of the brain to educate persons with cognitive impairment about changes in the brain. This knowledge may reinforce adherence to vascular risk factors management and to life style modifications to improve brain health (Grade 3C)

- We recommend against the use of functional MRI for the clinical investigation of patients presenting with cognitive complaint (Grade 1B)

- Magnetic resonance spectroscopy is not currently recommended for clinical use to make or differentiate a diagnosis of dementia in people presenting with mild cognitive impairment (Grade 2C).

FDG-PET and SPECT regional cerebral blood flow imaging

- For a patient with a diagnosis of dementia who has undergone the recommended baseline clinical and structural brain imaging evaluation and who has been evaluated by a dementia specialist but whose underlying pathological process is still unclear, preventing adequate clinical management, we recommend that the specialist obtains an ${ }^{18} \mathrm{~F}-\mathrm{FDG}$ PET scan for differential diagnosis purposes (Grade 1B)

- If such a patient cannot be practically referred for a FDG-PET scan, we recommend that a SPECT rCBF study be performed for differential diagnosis purposes (Grade 2C)

- There was only partial consensus for the proposition that for a patient with MCl evaluated by a dementia specialist and in whom clinical management would be influenced by evidence of an underlying neurodegenerative process, an ${ }^{18} \mathrm{~F}$-FDG PET scan be performed or, if not available, then a SPECT rCBF study be performed

PET amyloid imaging

- $\quad$ Although amyloid imaging represents a promising technique in the evaluation of dementia, there are many unknowns that could impact on its diagnostic utility and we therefore recommend that its use be restricted to research at present (Level 1C)

Other neuroimaging modalities

- Imaging biomarkers of neuroinflammation or tau pathology in dementia patients are not recommended in clinical practice. Although there is a growing body of literature supporting the use of dopamine presynaptic imaging agents for differentiating dementia with Lewy bodies from Alzheimer's disease, these imaging agents are not yet recommendable for clinical practice

CCCDTD4, Fourth Canadian Consensus Conference on the Diagnosis and Treatment of Dementia; CT, X-ray computerized tomography; ${ }^{18} \mathrm{~F}$-fluorine-18; FDG, fluorodeoxyglucose; MRI, magnetic resonance imaging; PET, positron emission tomography; rCBF, regional cerebral blood flow; SPECT, single-photon emission computed tomography.

with progressive cognitive impairment. These lesions are uncommon, with estimations at approximately $3 \%$ [15]. The Mini Mental State Examination score and physical functioning may improve in one-half of people with existing dementia after surgical drainage of a subdural hematoma [16].

A recent review reaffirmed several advantages of the enduring role of CT scan over MRI [17] in the clinical diagnosis of dementia, including lower cost, shorter duration of data acquisition, increased availability, ability to image patients with metallic devices, such as pacemakers, or who suffer from claustrophobia severe enough to prevent acquisition of MRI data.

One must emphasize that most available knowledge on CT scans has been obtained using older scanners that lacked the spatial resolution of newer, more powerful scanners. A study performed in a memory clinic setting compared the visual rating of hippocampal atrophy (HA) on coronal images, cortical atrophy on axial images and the assessment of white matter changes using a visual rating scale on a 64-detector-row CT scan, and on a $1.5 \mathrm{~T}$ MRI scan [18]. In that report, visual analysis of cortical and HA on CT scans was comparable with that obtained on matched brain MRI studies. In addition, the detection of white matter changes was also comparable for the two imaging modalities. There was no systematic difference between CT and MRI ratings on any of the scales that were used, including the estimation of HA.

\section{Structural magnetic resonance imaging Measurement of atrophy}

The characteristic neuropathological progression described by Braak and Braak [19] typically results in associated atrophy of the anterior parahippocampal gyrus, 
hippocampus and amygdala, followed by atrophy in multimodal association cortices. The structural imaging parameter with the strongest association in the literature to a diagnosis of $\mathrm{AD}$ is $\mathrm{HA}$. The $\mathrm{HA}$ parameter can be estimated either with complex, more or less automated volumetric MRI techniques, or with simple visual rating scales, using equivalent likelihood ratios [20]. MRI-defined HA has been incorporated in both the Dubois Criteria [21] and the new National Institute of Aging-Alzheimer's Association Criteria [7] for AD. Medial temporal lobe atrophy predicts progression from MCI to AD [22-25]. However, this diagnostic test has not yet been adopted widely in clinical settings. One of the main limitations of studies on the usefulness of HA measurements for evaluating the presence of AD pathology is that almost all of them come from referral cognitive disorder clinics, and the usefulness of HA in a more general setting has not been established [20].

Progressive atrophy measured on MRI is accepted as a biomarker of the progression of MCI to AD [26]. Rates of atrophy have been measured in the hippocampus and whole brain in a number of studies and have been reviewed recently [27]. Longitudinal studies of structural MRI aim to characterize the earliest regions affected by $\mathrm{AD}$ and their subsequent neuropathological progression and rate of change, as well as changes in regions of the neocortex as they progressively become involved [28-34]. A longitudinal study using MRI automatic segmentation of hippocampal volume, at three time points over 10 years in over 500 normal controls, showed that declining hippocampal volume predicted onset of clinical dementia [31]. Still, although longitudinal data are interesting, the predictive power of baseline MRI information is most useful to clinicians [25].

As a result of the marked contrast between cerebrospinal fluid and the surrounding tissues [35,36], ventricular enlargement - a consequence of atrophy - can be easily measured on MRI T1-weighted images and is another potential marker of progressing atrophy.

Manual segmentation to measure the hippocampal volume is recognized as the gold standard $[37,38]$. However, an initial survey of the 12 most cited manual segmentation protocols revealed a 2.5 -fold volume measurement difference [39]. Automated validated measures of hippocampal volume will help increase reproducibility of results. This increased reproducibility will not only increase the measures' diagnostic usefulness, but will also make it possible to use them as inclusion/exclusion criteria to enrich samples in trials testing therapeutic efficacy of different agents, allowing reduction of sample sizes $[40,41]$. Various automated methods to classify people with $\mathrm{AD}$ and MCI using structural MRI T1weighted images have been proposed and have been reviewed [32]. The authors concluded that most of the techniques accurately classified normal controls and subjects with AD. However, these methods had lower sensitivity in diagnosing prodromal AD.

Several recent review papers on structural MRI in AD have been published $[26,38,42]$.

\section{Structural neuroimaging in memory clinics}

The added value of neuroimaging in a memory disorders clinic has been evaluated in a retrospective study of 193 consecutively referred patients with cognitive impairment. Neuroimaging confirmed, clarified or contradicted the initial clinical diagnosis in more than $80 \%$ of patients. In $60 \%$ of the subjects, indicators of cerebrovascular disease were present [43].

When faced with the possibility of ordering brain imaging in the work-up of cognitive impairment, the clinician in a universal healthcare system such as that in Canada is faced with a dilemma: the values of social justice and allocation of resources must be balanced against the value of individual psychological benefits to patients and their families of investigating the symptoms in a thorough manner. This subjective benefit has not, to our knowledge, been assessed formally, but clinical experience suggests that patients with cognitive disorders expect some kind of brain imaging when they seek medical attention in this day and age.

There are no compelling reasons to withhold neuroimaging in the routine clinical assessment of cognitive impairment. The most obvious exception is situations where clinical management of vascular risk factors would not be modified if silent cerebrovascular lesions were revealed [15]. There is now documentation of the comparable value of the latest CT scanners compared with MRI for the routine work-up of dementia [18]. Head CT scanning is more widely available in Canada with typically shorter waiting lists than MRI and is sufficient for routine investigation of cognitive impairment (see CCCDTD4 recommendations in Table 1). MRI offers the advantage, however, of higher sensitivity to detect cerebrovascular lesions when compared with most currently used CT scanners, including in the detection of micro-bleeds on gradient-echo sequences [44], and this advantage will probably become stronger with the increasing availability of $3 \mathrm{~T}$ systems. Automated quantitative volumetrics and deformation-based protocols are also an advantage of MRI, but for the time being are mostly restricted to research settings $[45,46]$. The absence of ionizing radiation is another advantage of MRI. The higher resolution of MRI is preferred to detect specific patterns of cortical and subcortical atrophy in non-Alzheimer's dementia, such as fronto-temporal dementias $[47,48]$, multi-system atrophy or progressive supranuclear palsy [49]. For rarer disorders, different MRI specialized sequences can assist the diagnosis in human prion-linked dementia [50]. 
Again, the diagnostic value of specific HA measurements has been well established in referral clinic populations, but its diagnostic value has not been demonstrated in unselected primary care patients, and this will remain a challenge for the foreseeable future.

\section{Positron emission tomography fluorine-18- fluorodeoxyglucose and single-photon emission computed tomography cerebral blood flow studies}

Using the search strategy described above yielded 208 articles for positron emission tomography (PET) and 98 articles for single-photon emission computed tomography (SPECT).

\section{Positron emission tomography fluorine-18-fluorodeoxy- glucose versus single-photon emission tomography cerebral blood flow: a brief reminder}

PET imaging of the fluorine-18-fluorodeoxyglucose $\left({ }^{18} \mathrm{~F}\right.$ FDG) distribution is a reliable way of evaluating regional cerebral metabolic rates of glucose utilization, whereas SPECT imaging with either Technetium-99m-hexamethylene propyleneamine oxime or Technetium-99m-ethylene cisteinate dimer, the most frequently used agents, allows evaluation of regional cerebral blood flow (rCBF). Under most circumstances, rCBF and regional cerebral metabolic rate of glucose utilization are tightly coupled and represent the regional intensity of glutamatergic transmission [51]. Physiologically, therefore, these techniques can be considered generally equivalent, and the distribution patterns seen in neurodegenerative disorders as established over almost 30 years of their use are largely the same [52,53]. This equivalence also means that both approaches are subject to similar effects linked to age (see above) and to the influence of cerebral reserve [54], which must be factored in during clinical interpretation.

However, these two approaches are technically quite different. PET imaging has a strong advantage over SPECT in terms of spatial resolution. This translates into the ability to pick up earlier disease-linked alterations and is probably the main reason why PET displays a 15 to $20 \%$ better accuracy [55-57]. Resolution performances are still evolving - in fact with fewer possibilities for improvement with PET than with SPECT, which is closing in on the performances typically associated with PET, and SPECT is considered a valid diagnostic option [58]. At the same time, the major advantages of SPECT over PET - that is, its greater availability and lower cost are being eroded by the significantly increased availability of PET scanning.

Finally, remember that nuclear medicine techniques are minimally invasive. Their track record is remarkable, with 0.9 recorded acute, limited side-effects per 100,000 administrations [59]. The long-term risk of radiation exposure is that of developing cancer, a limited concern given the age of populations evaluated for dementia - the mean latent period for most solid tumors secondary to exposure to acute radiation exposure is reported at between 20 and 30 years, with an average risk of dying from such a tumor of $0.028 \%$ [60].

\section{Single-photon emission computed tomography regional cerebral blood flow studies}

Review articles since the last CCCDTD continue to report on nonattenuation corrected studies and come up with numbers for diagnostic accuracy that are of the same order as those cited in 2007: the pooled sensitivity and specificity are reported at around $75 \%$ and $90 \%$, respectively $[2,57]$.

Recent papers have confirmed the ability of SPECT rCBF studies to efficiently differentiate AD from other causes of dementia/cognitive impairment, such as vascular dementia and fronto-temporal dementia [61,62]. The differential diagnosis between $\mathrm{AD}$ and depression with cognitive impairment appears less optimal, in fact raising the possibility of a direct link between neurodegeneration and depression [63]. Differentiating dementia with Lewy bodies (DLB) from AD on the basis of hypoperfusion of the visual cortex also appears established [64], although the sensitivity and specificity (65\% and $80 \%$, respectively) might be suboptimal [58].

Differentiation of DLB from AD with SPECT agents targeting the dopamine cell membrane transporter is available in Europe and the USA but not in Canada. A complete review on the subject has recently confirmed the usefulness of this approach [65]; cases showing unclear results with that agent are likely to represent combined AD/DLB pathology.

The ability of SPECT rCBF to predict clinical evolution is discussed by different authors, with variable conclusions. In AD, rapidity of progression can be inferred from the initial rCBF pattern [66]. However, prediction of conversion from MCI to dementia of the Alzheimer type with rCBF studies is not clearly established at this time, the results being discordant $[67,68]$. Still, differences of rCBF patterns are seen in MCI subtypes with different risk of progressing to $\mathrm{AD}$ [69], suggesting that brain perfusion studies can probably predict progression of cognitive deterioration.

Computer-assisted image analysis is an important issue impacting on the clinical usefulness of rCBF SPECT imaging. Multiple techniques have been proposed to facilitate interpretation. It is virtually impossible to determine from currently available data whether one approach is better than another, as head-to-head comparisons are not generally available. When they are, differences are limited and of uncertain cause [70]. Ultimately, the most important question is whether such approaches are superior to visual evaluation. Invariably, the impact on 
accuracy is more significant for less experienced interpreters than for those regularly reporting such studies [71].

Positron emission tomography fluorine-18-fluorodeoxyglucose Numerous reviews of the application of PET ${ }^{18} \mathrm{~F}-\mathrm{FDG}$ imaging to the evaluation of dementia have been published, reporting on large numbers of subjects, sometimes expressing wonderment at the ongoing questioning the technique still faces [72].

A recent review covers the period from 2000 to the latter half of 2011 [73]. The methodology employed is similar to that proposed here, and the conclusions are close to those we arrived at when covering, along with the previous CCCDTD report, the same material. Eleven studies meeting standard meta-analysis criteria were identified. Those studies report on hundreds of subjects (the exact number is difficult to specify as some cohorts come from the same centers and probably contain many of the same patients) who have been classified, based on different diagnostic criteria (autopsy results, clinical follow-up, clinical assessment), as AD, healthy controls, or bearers of other dementia-associated conditions.

From the five case-control studies reviewed, all at American Academy of Neurology diagnostic evidence level III, the pooled sensitivity, specificity and accuracy for the diagnosis of AD were respectively $96 \%, 90 \%$ and $93 \%$. From the two longitudinal studies, sensitivity results were $78 \%$ and $91.7 \%$ for the presence of dementia, with specificities of $81 \%$ and $88.9 \%$. For the two pathologycontrolled studies looking at the presence or absence of $\mathrm{AD}$, sensitivities were $94 \%$ and $84 \%$, and specificities were $73 \%$ and $74 \% .{ }^{18} \mathrm{~F}$-FDG imaging differentiated AD from other dementia-causing conditions with accuracies ranging from 79 to $93 \%$.

Such percentages increase physicians' confidence in the diagnosis given to a patient above the level associated with purely clinical approaches. Diagnosis is helped significantly in over $70 \%$ of cases in a memory clinic setting, particularly in cases of atypical/unclear dementias [74].

Predicting clinical evolution from ${ }^{18} \mathrm{~F}-\mathrm{FDG}$ studies in patients with cognitive disorders remains an important clinical objective. Clinical identification of nondemented patients at risk of evolving to $\mathrm{AD}$ in general involves recognizing the presence of amnestic $\mathrm{MCI}$, but not all amnestic MCI evolve to AD [75]. A normal PET study predicts with very high accuracy a low risk of cognitive deterioration for a number of years $[35,76,77]$. Subjects at high risk for $\mathrm{AD}$, members of families with familial $\mathrm{AD}$ $[78,79]$ and nondemented subjects with evidence of brain accumulation of $\beta$-amyloid [80] can show changes in ${ }^{18} \mathrm{~F}$ FDG studies comparable with those seen in AD subjects years before cognitive deterioration, as do many amnestic MCI subjects (at high risk of evolving to AD) [81], suggesting that such a pattern might indeed carry prognostic information. Clinical follow-up of amnestic $\mathrm{MCI} /$ pre-amnestic MCI subjects shows that the initial ${ }^{18} \mathrm{~F}$-FDG study is a strong predictor of conversion to $\mathrm{AD}$ or cognitive decline [82-85]. ${ }^{18} \mathrm{~F}-\mathrm{FDG}$ might in fact be one of the better AD biomarkers in terms of its ability to follow cognitive decline throughout the course of the disease [86]. Improved specificity in that domain might come from supplemental information provided by $\beta$ amyloid PET imaging [87-89].

A practical issue arising from the previous discussion is the value of repeated imaging when an initial PET study is interpreted as normal or inconclusive for the presence of a dementing process. Very little information is available in that area but, should a second study be performed, results from one group suggest that absence progression over 1 year goes against the presence of an active neurodegenerative process [90].

Other diseases can present with cognitive impairment aside from $\mathrm{AD}$, vascular dementia, fronto-temporal dementia and DLB - in particular, those that present with movement disorders often mimicking early Parkinson's disease (multisystem atrophy, cortical basal ganglia degeneration, progressive supranuclear palsy). Patients affected by those diseases are sometimes referred for evaluation of accompanying cognitive decline. Although the literature is much more limited on that topic than it is for other conditions affecting cognition, there is evidence that specific brain metabolism patterns can be seen with PET ${ }^{18} \mathrm{~F}$-FDG imaging [91,92].

Just as with SPECT, multiple computer-assisted interpretation schemes have been proposed for ${ }^{18} \mathrm{~F}$-FDG studies, some having achieved significant and well deserved acceptance [93]. Numerous technical issues remain to be settled in that field, including the nature of the reference population being used for comparison purposes [94], pointing to a pressing need for standardization. In general, the same principles seem to apply here as were already discussed for SPECT; that is, such approaches seem to be particularly clinically helpful when used by observers with limited experience (clinical visual interpretation of those tests being subject to significant variability [95]) or in research settings [96].

\section{Amyloid imaging \\ Introduction}

PET imaging with amyloid ligands allows in vivo detection of amyloid plaques, a core pathologic feature of $\mathrm{AD}$ [97]. Although the 20-minute physical half-life of carbon11-labelled Pittsburgh Compound B (PiB) has limited its use to research centers equipped with a cyclotron, a second generation of amyloid agents labeled with ${ }^{18} \mathrm{~F}$ (110-minute half-life) has recently been developed, making it feasible to produce and distribute tracers for 
clinical use. In April $2012{ }^{18} \mathrm{~F}$-florbetapir became the first US Food and Drug Administration-approved ${ }^{18} \mathrm{~F}$ amyloid tracer, and was approved by European authorities in early 2013. Higher nonspecific white matter binding has been reported with ${ }^{18} \mathrm{~F}$ amyloid agents (flutemetamol, florbetapir, and florbetaben) but not with AZD4694 [98]. All have shown performances comparable with those of $\mathrm{PiB}$ in clinical populations, and high correlation with postmortem measures of fibrillar amyloid-beta has been found [99].

\section{Amyloid positron emission tomography in various clinical populations}

Cognitively normal older individuals show elevated $\mathrm{PiB}$ binding in 10 to $34 \%$ of cases, a rate similar to that observed for amyloid pathology in autopsy studies [100]. Although the significance of a positive amyloid scan in cognitively normal individuals remains uncertain, crosssectional studies have shown AD-like brain changes (hippocampal and temporal-parietal atrophy) while early longitudinal data have strengthened the notion that many such subjects are in a preclinical phase of AD. At present, there is no clinical indication for amyloid imaging in cognitively normal individuals or for the initial investigation of cognitive complaints.

Current data in MCI patients indicate that amyloid imaging provides prognostic information, presumably by identifying patients with underlying AD pathology [101]. As a group, MCI cases show elevated $\mathrm{PiB}$ binding in 52 to $87 \%$ of cases, with a regional distribution similar to that found in $\mathrm{AD}$. In the largest longitudinal effort to date [102], the conversion rate was $82 \%$ in those with increased PiB uptake, but only $7 \%$ in PiB-negative subjects.

Most studies in AD have found very high $(\geq 90 \%) \mathrm{PiB}-$ PET sensitivity, with a pattern that closely mirrors the distribution of plaques found at autopsy [103]. Much like FDG-PET [75], amyloid imaging will probably not add value to the diagnostic work-up of patients with straightforward clinical AD, but is likely to be useful in patients with atypical complex presentations or early ageof-onset dementia. Considering that frontal temporal lobar degeneration and $\mathrm{AD}$ are the leading causes of dementia in young patients, that distinguishing the two during life can be clinically challenging, and that amyloidbeta plaques are not part of the frontal temporal lobar degeneration pathologic spectrum, authors have shown a valuable role for amyloid imaging in the differential diagnosis of these conditions, providing information beyond that obtained with ${ }^{18}$ FDG-PET [104]. Other clinical conditions studied with amyloid PET include vascular dementia, cerebral amyloid angiopathy, Parkinson's disease dementia, and DLB, but a detailed discussion of results in those conditions is beyond the scope of this article (see [105] for a more detailed review).

\section{Amyloid positron emission tomography in clinical practice:} unresolved questions and recommendations

Amyloid imaging represents a promising technique in the evaluation of dementia but many ill-defined factors can probably impact its diagnostic validity and utility [106]. Currently, the only country where amyloid imaging is approved by government authorities is the USA. Clinicians from nearby countries such as Canada may therefore be called upon to interpret results from amyloid tests performed on their patients. Physicians should be very cautious in their interpretation because, used in isolation, this test cannot diagnose $\mathrm{AD}$ or $\mathrm{MCI}$, or differentiate normal from abnormal aging. Recommendations are that the physicians consult with a dementia specialist familiar with this technique when confronted with amyloid imaging reports for studies performed in a region where they are available. Should amyloid imaging become more widely available, it is unlikely to become a routine test. Rather, it will probably be part of a comprehensive evaluation for complex and atypical cases referred to tertiary-care memory clinics when a more accurate clinical diagnosis is needed.

Although surveys suggest that rates of cholinesterase prescription in people with $\mathrm{AD}$ range from about 10 to $50 \%$ depending on the country, it is our clinical impression that inhibitors are prescribed to a large number of patients with non-AD dementia unlikely to benefit from such therapy, while certain populations that could indeed benefit remain untreated (for example, MCI due to AD). A decision to treat might be arrived at in a more rational fashion if amyloid PET was applied in the right circumstances, such as in atypical cognitive disorders and dementias [106]. This application could possibly result in significant savings, but further cost-effectiveness studies are required. The more immediate impact of amyloid imaging, however, will probably be improving clinical trial design by enrolling patients based on biological, rather than clinical, phenotype. A positive amyloid scan could well become the primary inclusion criterion for a study focused on prevention of AD progression.

Since the CCCDTD4 meeting, an important consensus paper has been published by the Amyloid Imaging Taskforce to provide guidance to dementia care practitioners, patients, and caregivers on appropriate use of amyloid PET [107]. A set of criteria were agreed upon that define the types of patients and clinical circumstances in which amyloid PET could be used. Both appropriate and inappropriate uses are considered and discussed. Future research directions are also outlined, including diagnostic utility and patient-centered outcomes. This consensus paper is generally in line with the CCCDTD4 recommendations, but one should remember that no amyloidimaging tracer is approved in Canada at this time, or in fact being considered for approval. 


\section{Conclusion}

Neuroimaging is now a major diagnostic player in the evaluation of subjects reporting cognitive decline, in large part because the technique no longer is called upon solely to rule out non-neurodegenerative causes, but rather to positively identify neurodegeneration by probing for a series of anatomical and functional modifications it inflicts on the brain. Although stronger confirmation is always desirable, enough data are available on the value of HA assessment with MRI, or of metabolic/blood flow disturbances with PET and SPECT, to differentiate AD from other processes and to recommend using such techniques when diagnosis remains doubtful and clinical management is therefore undefined in selected cases. Amyloid imaging will also contribute to that process, although its optimal use remains to be clarified. All of those techniques will also benefit the clinical evaluation of potentially disease-modifying therapies, as well as help to develop a better clinical understanding of neurodegenerative processes as such. The recommendations from the CCCDTD4 meeting, which were based on the review presented above and on some additional texts found at the website [3], are, once again, summarized in Table 1.

\begin{abstract}
Abbreviations
AD, Alzheimer's disease; CCCDTD, Canadian Consensus Conference on the Diagnosis and Treatment of Dementia; CT, X-ray computerized tomography; DLB, dementia with Lewy bodies; ${ }^{18} \mathrm{~F}$-fluorine-18; FDG, fluorodeoxyglucose; $\mathrm{HA}$, hippocampal atrophy; $\mathrm{MCl}$, mild cognitive impairment; $\mathrm{MRI}$, magnetic resonance imaging; $P E T$, positron emission tomography; $\mathrm{PiB}$, Pittsburgh compound B; rCBF, regional cerebral blood flow; SPECT, single-photon emission computed tomography.
\end{abstract}

\section{Competing interests}

The authors declare that they have no competing interests.

\section{Acknowledgments}

RB would like to acknowledge the Ivey-BMO Financial Group Scientist in Brain Disorders Imaging Award. RL Jr would like to acknowledge Dr Gil D Rabinovici for earlier comments on the amyloid imaging section. PR-N acknowledges support from Le Fonds de recherche du Québec - Santé chercheurs-boursiers program, the Canadian Institutes of Health Research, the Alzheimer's Association and the Aisenstadt Foundation.

\section{Declarations}

This article has been published as part of Alzheimer's Research \& Therapy Volume 5 Supplement 1, 2013: Background documents to the 4th Canadian Consensus Conference on the Diagnosis and Treatment of Dementia (CCCDTD4). The full contents of the supplement are available online at http://alzres.com/supplements/5/S1.

Publication charges for the supplement were funded by the Canadian Consensus Conference on the Diagnosis and Treatment of Dementia (CCCDTD). Although residual conference funds used include contributions from pharmaceutical companies, no commercial organization has been involved in the selection of participants, choice of topics, preparation of background papers or recommendations. In kind support was also provided by the Canadian Dementia Knowledge Translation Network, and the offices of Drs Serge Gauthier (McGill University), Christopher Patterson (McMaster University) and Howard Chertkow (McGill University), whose role as Guest Editors involved the coordination of the project without involvement in the journal's standard peer review process which applied for all articles.

\section{Authors' contributions}

J-PS was primarily responsible for the nuclear medicine (PET- ${ }^{18} \mathrm{~F}-\mathrm{FDG}$ and SPECT rCBF and others) section, as well as for putting together the different parts of the manuscript. MB and CB were primarily responsible for the structural imaging section. RL Jr was primarily responsible for the amyloid imaging section. All authors, including those not primarily responsible for a given section (AMB, RB, PR-N), reviewed the manuscript and contributed their comments to all sections.

\section{Author details}

${ }^{1}$ PET Unit, McConnell Brain Imaging Centre, Montreal Neurological Institute, McGill University, 3801 University Street, Montreal, Quebec, Canada H3A 2 B4. ${ }^{2}$ Robarts Research Institute, Western University, London, Ontario, Canada. ${ }^{3}$ Service de Neurologie, Centre hospitalier universitaire de Sherbrooke, Sherbrooke, Quebec, Canada. ${ }^{4}$ Department of Medicine, Division of Geriatric Medicine, Western University, London, Ontario, Canada. ${ }^{5}$ Clinique Interdisciplinaire de Mémoire, Département des Sciences Neurologiques, CHU de Québec, Université Lava, Quebec, Quebec, Canada. ${ }^{\top}$ Translational Neuroinmaging Laboratory, McGill Centre for Studies in Aging, Douglas Research Institute, McGill University, Montreal, Quebec, Canada.

Published: 8 July 2013

\section{References}

1. Chow T: Structural neuroimaging in the diagnosis of dementia. Alzheimers Dement 2007, 3:333-335.

2. Borrie M: Functional neuroimaging in the diagnosis of dementia. Alzheimers Dement 2007, 3:336-340.

3. 2012 Canadian Consensus conference on Dementia [http://www.cccdtd.ca]

4. Knopman DS, DeKosky ST, Cummings JL, Chui H, Corey-Bloom J, Relkin N, Small GW, Miller B, Stevens JC: Practice parameter: diagnosis of dementia (an evidence-based review). Report of the Quality Standards Subcommittee of the American Academy of Neurology. Neurology 2001, 56:1143-1153.

5. Dementia: Supporting People with Dementia and their Carers in Health and Social Care [http://guidance.nice.org.uk/CG42].

6. Waldemar G, Dubois B, Emre M, Georges J, McKeith IG, Rossor M, Scheltens P, Tariska P, Winblad B: Recommendations for the diagnosis and management of Alzheimer's disease and other disorders associated with dementia: EFNS guideline. Eur J Neuro/ 2007, 14:e1-e26.

7. McKhann GM, Knopman DS, Chertkow H, Hyman BT, Jack CR Jr, Kawas CH, Klunk WE, Koroshetz WJ, Manly JJ, Mayeux R, Mohs RC, Morris JC, Rossor MN, Scheltens P, Carrillo MC, Thies B, Weintraub S, Phelps CH: The diagnosis of dementia due to Alzheimer's disease: recommendations from the National Institute on Aging and the Alzheimer's Association workgroup. Alzheimers Dement 2011, 7:263-269.

8. Albert MS, DeKosky ST, Dickson D, Dubois B, Feldman HH, Fox NC, Gamst A, Holtzman DM, Jagust WJ, Petersen RC, Snyder PJ, Carrillo MC, Thies B, Phelps $\mathrm{CH}$ : The diagnosis of mild cognitive impairment due to Alzheimer's disease: recommendations from the National Institute on AgingAlzheimer's Association workgroups on diagnostic guidelines for Alzheimer's disease. Alzheimers Dement 2011, 7:270-279.

9. Mendez MF, Shapira JS, McMurtray A, Licht E: Preliminary findings: behavioral worsening on donepezil inpatients with frontotemporal dementia. Am J Geriatr Psychiatry 2007, 15:84-87.

10. McKeith I, Fairbairn A, Perry R, Thompson P, Perry E: Neuroleptic sensitivity inpatients with senile dementia of Lewy body type. BrMed J 1992, 305:673-678

11. Kushner H: Frontotemporal dementia and primary progressive aphasia: an update. Curr Neurol Neurosci Rep 2010, 10:504-511.

12. Fotuhi M, Hachinski V, Peter J. Whitehouse PJ: Changing perspectives regarding late-life dementia. Nat Rev Neurol 2009, 5:649-658.

13. Savva GM, Wharton SB, Ince PG, Ince PG, Forster G, Matthews FE, Brayne C: Age, neuropathology, and dementia. N Engl J Med 2009, 360:2302-2309.

14. Hort J, O'Brien JT, Gainotti G, Pirttila T, Popescu BO, Rektorova I, Sorbi S, Scheltens P: EFNS guidelines for the diagnosis and management of Alzheimer's disease. Eur J Neurol 2010,17:1236-1248.

15. Sitoh YY, Kanagasabai K, Earnest A, Sahadevan S: Evaluation of dementia: the case for neuroimaging all mild to moderate cases. Ann Acad Med Singapore 2006, 35:383-389.

16. Ishikawa E, Kiyoyuki Y, Sugimoto K, Ayuzawa S, Nose T: Reversible dementia 
in patients with chronic subdural hematomas. J Neurosug 2002, 96:680-683.

17. Pasi M, Poggesi A, Pantoni L: The use of CT in dementia. Int Psychogeriatr 2011, 23(Suppl 2):S6-S12.

18. Wattjes MP, Henneman WJP, van der Flier WM, de Vries O, Träber F, Geurts JJ, Scheltens P, Vrenken H, Barkhof F: Diagnostic imaging of patients in a memory clinic: comparison of MR imaging and 64-detector row $\mathrm{CT}$. Radiology 2009, 253:174-183.

19. Braak H, Braak E: Neuropathological staging of Alzheimer-related changes. Acta Neuropathol 1991, 82:239-259.

20. Wahlund LO, Almkvist O, Blennow K, Engedahl K, Johansson A, Waldemar G, Wolf $\mathrm{H}$ : Evidence-based evaluation of magnetic resonance imaging as a diagnostic tool in dementia workup [meta-analysis review]. Top Magn Reson Imaging 2005, 16:427-437.

21. Dubois B, Feldman HH, Jacova C, Dekosky ST, Barberger-Gateau P, Cummings J, Delacourte A, Galasko D, Gauthier S, Jicha G, Meguro K, O'Brien J, Pasquier F, Robert P, Rossor M, Salloway S, Stern Y, Visser PJ, Scheltens P: Research criteria for the diagnosis of Alzheimer's disease: revisiting the NINCDS-ADRDA criteria. Lancet Neurol 2007, 6:734-746.

22. Scheltens $P$, Leys $D$, Barkhof F, Huglo D, Weinstein HC, Vermersch P, Kuiper $M$, Steinling M, Wolters EC, Valk J: Atrophy of medial temporal lobes on MRI in 'probable' Alzheimer's disease and normal ageing: diagnostic value and neuropsychological correlates. J Neurol Neurosurg Psychiatry 1992, 55:967-972

23. DeCarli C, Frisoni GB, Clark CM, Harvey D, Grundman M, Petersen RC, Thal L, Jin S, Jack CR Jr, Scheltens P; Alzheimer's Disease Cooperative Study Group: Qualitative estimates of medical temporal atrophy as a predictor of progression from mild cognitive impairment to dementia. Arch Neurol 2007, 64:108-115.

24. Duara R, Loewenstein DA, Potter E, Appel J, Greig MT, Urs R, Shen Q, Raj A, Small B, Barker W, Schofield E, Wu Y, Potter H: Medial temporal lobe atrophy on MRI scans and the diagnosis of Alzheimer disease. Neurology 2008 71:1986-1992

25. Duchesne S, Bocti C, De Sousa K, Frisoni GB, Chertkow H, Collins DL: Amnestic MCl future clinical status prediction using baseline MRI features. Neurobiol Aging 2010, 31:1606-1617.

26. Frisoni GB, Fox NC, Jack CR, Scheltens P, Thompson PM: The clinical use of structural MRI in Alzheimer disease. Nat Rev Neurol 2010, 6:67-77.

27. Jack CR, Wiste HJ, Vemuri P, Weigand SD, Senjem ML, Zeng G, Bernstein MA, Gunter JL, Pankratz VS, Aisen PS, Weiner MW, Petersen RC, Shaw LM, Trojanowski JQ, Knopman DS: Brain beta-amyloid measure and magnetic resonance imaging atrophy both predict time-to-progression from mild cognitive impairment to Alzheimer's disease. Brain 2010, 133:3336-3348,

28. Fox NC, Black RS, Gilman S, Rossor MN, Griffith SG, Jenkins L, Koller M: Effects of $A B$ immunization (AN1792) on MRI measures of cerebral volume in Alzheimer Disease. Neurology 2005, 64:1563-1572.

29. Whitwell JL, Przybelski SA, Weigand SD, Knopman DS, Boeve BF, Petersen RC, Jack CR Jr: 3D maps from multiple MRI illustrate changing atrophy patterns as subjects progress from mild cognitive impairment to Alzheimer's disease. Brain 2007, 130:1777-1786.

30. Hall AM, Moore RY, Lopez OL, Kuller L, Becker JT: Basal forebrain atrophy is a presymptomatic marker for Alzheimer's disease. Alzheimers Dement 2008, 4:271-279.

31. Den Heijer T, van der Lign F, Koustaal PJ, Hofman A, van der Lugt A, Krestin GP, Niessen WJ, Breteler MM: A 10-year follow-up of hippocampal volume on magnetic resonance imaging in early dementia and cognitive decline. Brain 2010, 133:1163-1172.

32. Cuingnet R, Gerardin E, Tessieras J, Auzias G, Lehéricy S, Habert MO, Chupin $\mathrm{M}$, Benali $\mathrm{H}$, Colliot O: Automatic classification of patients with Alzheimer's disease from structural MRI: a comparison of ten methods using the ADNI database. Neurolmage 2011, 56:766-781.

33. Li X, Coyle D, Maguire L, Watson DR, McGinnity TM: Gray matter concentration and effective connectivity changes in Alzheimer's disease: a longitudinal structural MRI study. Neuroradiology 2011, 53:733-748.

34. Tondelli M, Wilcock GK, Nichelli P, De Jager CA, Jenkinson M, Zamboni G: Structural MRI changes detectable up to ten years before clinical Alzheimer's disease. Neurobiol Aging 2012, 33:825.e25-825.e36.

35. Nestor SM, Rupsingh R, Borrie M, Smith M, Accomazzi V, Wells JL, Fogarty J, Bartha R: Ventricular enlargement as a possible measure of Alzheimer's disease progression validated using the Alzheimer's Disease Neuroimaging Initiative database. Brain 2008, 131:2443-2454

36. Ridha BH, Anderson VM, Barnes J, Boyes RG, Price SL, Rossor MN, Whitwell JL,
Jenkins L, Black RS, Grundman M, Fox NC: Volumetric MRI and cognitive measures in Alzheimer disease: comparison of markers of progression. J Neurol 2008, 255:567-574.

37. Frisoni GB, Jack CR: Harmonization of magnetic resonance-based manual hippocampal segmentation: a mandatory step for wide clinical use. Alzheimers Dement 2011, 7:171-174.

38. Jack CR, Barkhof F, Bernstein MA, Cantillon M, Cole PE, Decarli C, Dubois B, Duchesne S, Fox NC, Frisoni GB, Hampel H, Hill DL, Johnson K, Mangin JF, Scheltens P, Schwarz AJ, Sperling R, Suhy J, Thompson PM, Weiner M, Foster $\mathrm{NL}$ : Steps to standardization and validation of hippocampal volumetry as a biomarker in clinical trials and diagnostic criterion for Alzheimer's disease. Alzheimers Dement 2011, 7:474-485.

39. Boccardi M, Ganzola R, Bocchetta M, Pievani M, Redolfi A, Bartzokis G, Camicioli R, Csernansky JG, de Leon MJ, deToledo-Morrell L, Killiany RJ, Lehéricy S, Pantel J, Pruessner JC, Soininen H, Watson C, Duchesne S, Jack CR $\mathrm{Jr}$, Frisoni GB: Survey of protocols for the manual segmentation of the hippocampus: preparatory steps towards a joint EADC-ADNI Harmonized Protocol. J Alzheimers Dis 2011, 26:61-75.

40. Hampel H, Frank R, Broich K, Teipel SJ, Katz RG, Hardy J, Herholz K, Bokde AL, Jessen F, Hoessler YC, Sanhai WR, Zetterberg H, Woodcock J, Blennow K: Biomarkers for Alzheimer's disease: academic, industry and regulatory perspectives. Nat Rev Drug Discov 2010, 9:560-574.

41. McEvoy LK, Edland SD, Holland D, Hagler DJ Jr, Roddey JC, FennemaNotestine C, Salmon DP, Koyama AK, Aisen PS, Brewer JB, Dale AM: Neuroimaging enrichment strategy for secondary prevention trials in Alzheimer disease. Alzheimers Dis Assoc Disord 2010, 24:269-277.

42. Wattjes MP: Structural MRI. Int Psychogeriatr 2011, 23(Suppl 2):S13-S24.

43. Borghesani PR, DeMers SM, Manchanda V, Pruthi S, Lewis DH, Borson S: Neuroimaging in the clinical diagnosis of dementia: observations from a memory disorders clinic. J Am Geriatr Soc 2010, 58:1453-1458.

44. Cordonnier C, van der Flier WM: Brain microbleeds and Alzheimer's disease: innocent observation or key player? Brain 2011, 134:335-344.

45. Ramirez J, Gibson E, Quddus A, Lobaugh NJ, Feinstein A, Levine B, Scott CJ, Levy-Cooperman N, Gao FQ, Black SE: Lesion Explorer: a comprehensive segmentation and parcellation package to obtain regional volumetrics for subcortical hyperintensities and intracranial tissue. Neuroimage 2011 54:963-973

46. Coupe P, Eskildsen SF, Manjon JV, Fonov VS, Collins DL: Simultaneous segmentation and grading of anatomical structures for patient's classification: application to Alzheimer's disease. Neurolmage 2012, 59:3736-3747

47. Bocti C, Rockel C, Roy P, Gao F, Black SE: Topographical patterns of lobar atrophy in frontotemporal dementia and Alzheimer's disease. Dement Geriatr Cogn Disord 2006, 21:364-372.

48. Du AT, Schuff N, Kramer JH, Rosen HJ, Gorno-Tempini ML, Rankin K, Miller BL, Weiner MW: Different regional patterns of cortical thinning in Alzheimer's disease and frontotemporal dementia. Brain 2007, 130:1159-1166.

49. Rolland Y, Verin M, Payan CA, Duchesne S, Kraft E, Hauser TK, Jarosz J, Deasy N, Defevbre L, Delmaire C, Dormont D, Ludolph AC, Bensimon G, Leigh PN: A new MRI rating scale for progressive supranuclear palsy and multiple system atrophy: validity and reliability. J Neurol Neurosurg Psychiatry 2011, 82:1025-1032

50. Carswell C, Thompson A, Lukic A, Stevens J, Rudge P, Mead S, Collinge J, Hyare H: MRI findings are often missed in the diagnosis of CreutzfeldtJakob disease. BMC Neurol 2012, 12:153.

51. Sibson NR, Dhankhar A, Mason GF, Rothman DL, Behar KL, Shulman RG: Stoichiometric coupling of brain glucose metabolism and glutamatergic neuronal activity. Proc Natl Acad Sci U S A 1998, 95:316-321.

52. Alavi A, Reivich M, Ferris S Christman D, Fowler J, MacGregor R, Farkas T, Greenberg J, Dann R, Wolf A: Regional cerebral glucose metabolism in aging and senile dementia as determined by ${ }^{18} \mathrm{~F}$-deoxyglucose and positron emission tomography. Ex Brain Res 1982, Suppl 5:187-195.

53. Gemmel HG, Sharp PF, Evans NT Besson JA, Lyall D, Smith FW: Single photon emission tomography with ${ }^{123}$-isopropylamphetamine in Alzheimer's disease and multi-infarct dementia. Lancet 1984, 324:1348.

54. Katzman R: Education and the prevalence of dementia and Alzheimer's disease. Neurology 1993, 43:13-20

55. Herholz K, Schopphoff H, Schmidt M, Mielke R, Eschner W, Scheidhauer K, Schicha H, Heiss WD, Ebmeier K: Direct comparison of spatially normalized PET and SPECT scans in Alzheimer's disease. J Nucl Med 2002, 43:21-26.

56. Silverman DHS: Brain ${ }^{18} \mathrm{~F}-\mathrm{FDG}$ PET in the diagnosis of neurodegenerative 
dementias: comparison with perfusion SPECT and with clinical evaluations lacking nuclear imaging. J Nucl Med 2004, 45:594-607.

57. Morinaga A, Ono K, Ikeda T, Ikeda Y, Shima K, Noguchi-Shinohara M, Samuraki M, Yanase D, Yoshita M, I wasa K, Mastunari I, Yamada M: A comparison of the diagnostic sensitivity of MRI, CBF-SPECT, FDG-PET and cerebrospinal fluid biomarkers for detecting Alzheimer's disease in a memory clinic. Dement Geriatr Cogn Disord 2010, 30:285-292.

58. Farid K, Caillat-Vigneron N, Sibon I: Is brain SPECT useful in degenerative dementia diagnosis? J Comput Assist Tomogr 2011, 35:1-3.

59. Matsuda H, Arano Y, Okazawa H, Okamura T, Mizumura S, Yokoyama K: The $30^{\text {th }}$ report on survey of the adverse reaction to radiopharmaceuticals. Kaku lgaku 2009, 46:29-41.

60. Mettler FA, Upton AC: Cancer induction and dose-response models. In Medical Effects of lonizing Radiotion. 3rd edition. Edited by Mettler FA, Upton AC. Philadelphia: Saunders-Elsevier; 2008:71-116.

61. Waragai M, Mizumura S, Yamada T, Matsuda H: Differentiation of early-stage Alzheimer's disease from other types of dementia using brain perfusion single photon emission computed tomography with easy Z-Score imaging system analysis. Dement Geriatr Cogn Disord 2008, 26:547-555.

62. McNeill R, Sare GM, Manoharan M, Testa HJ, Mann DM, Neary D, Snowden JS, Varma AR: Accuracy of single-photon emission computed tomography in differentiating frontotemporal dementia from Alzheimer's disease. J Neurol Neurosurg Psychiatry 2007, 78:350-355.

63. Staffen W, Bergmann J, Schönauer U, Zauner H, Kronbichler M, Golaszewski S, Ladurner G: Cerebral perfusion (HMPAO-SPECT) in patients with depression with cognitive impairment versus those with mild cognitive impairment and dementia of Alzheimer's type: a semiquantitative and automated evaluation. Eur J Nucl Med Mol Imaging 2009, 36:801-810.

64. Tateno M, Utsumi K, Kobayashi S, Takahashi A, Saitoh M, Morii H, Fujii K, Teraoka M: Usefulness of a blood flow analyzing program 3DSRT to detect occipital hypoperfusion in dementia with Lewy bodies. Progr Neuro-Psychopharmacol Biol Psychiatry 2008, 32:1206-1209.

65. Cummings JL, Henchcliffe C, Schaier S, Simuni T, Waxman A, Kemp P: The role of dopaminergic imaging in patients with symptoms of dopaminergic system neurodegeneration. Brain 2011, 134:3146-3166.

66. Hanyu H, Sato T, Hirao K, Kanetaka H, Iwamoto T, Koizumi K: The progression of cognitive deterioration and regional cerebral blood flow patterns in Alzheimer's disease: a longitudinal SPECT study. J Neurol Sci 2010, 290:98-101

67. Caroli A, Testa C, Geroldi C, Nobili F, Barnden LR, Guerra UP, Bonetti M, Frisoni $\mathrm{GB}$ : Cerebral perfusion correlates of conversion to Alzheimer's disease in amnestic mild cognitive impairment. J Neurol 2007, 254:1698-1707.

68. Devanand DP, Van Heertum RL, Kegeles L,S Liu X, Jin ZH, Pradhaban G, Rusinek H, Pratap M, Pelton GH, Prohovnik I, Stern Y, Mann JJ, Parsey R: ${ }^{99 m}$ Tc hexamethyl-propylene-aminoxime single-photon emission computed tomography prediction of conversion from mild cognitive impairment to Alzheimer disease. Am J Geriatr Psychiatry 2010, 18:959-972.

69. Nobili F, Frisoni GB, Portet F, Verhey F, Rodriguez G, Caroli A, Touchon J, Calvini P, Morbelli S, De Carli F, Guerra UP, Van de Pol LA, Visser PJ: Brain SPECT in subtypes of mild cognitive impairment - findings from the DESCRIPA multicenter study. J Neurol 2008, 255:1344-1353.

70. Nishimiya M, Matsuda H, Imabayashi E, Kuji I, Sato N: Comparison of SPM and NEUROSTAT in voxelwise statistical analysis of brain SPECT and MRI at the early stage of Alzheimer's disease. Ann Nucl Med 2008, 22:921-927.

71. 71. Ebmeier KP, Darcourt K, Dougall NSNJ, Glabus MF, Herholz K, Koulibaly PM, Migneco O, Nobili F, Pupi A, Robert P, Rodriguez G, Scheidhauer K: Voxelbased approaches in clinical imaging. In: SPECT in Dementia. Volume 22. Edited by Ebmeier KP. Basel: Karger; 2003:72-85.

72. Lucignani G, Nobili F: FDG-PET for early assessment of Alzheimer's disease: isn't the evidence base large enough? Eur J Nucl Med Mol Imaging 2010, 37:1604-1609

73. Bohnen NI, Djang DSW, Herholz K, Anzai Y, Minoshima S: Effectiveness and safety of ${ }^{18}$ F-FDG PET in the evaluation of dementia: a review of the recent literature. J Nucl Med 2012, 53:59-71

74. Laforce R, Buteau JP, Paquet N, Verret L, Houde M, Bouchard RW: The value of PET in mild cognitive impairment, typical and atypical/unclear dementias: a retrospective memory clinic study. Am J Alzheimers Dis Other Dement 2010, 25:324-332.

75. Cummings JL, Doody R, Clark C: Disease-modifying therapies for Alzheimer disease: challenges to early intervention. Neurology 2007, 69:1622-1634.

76. Herholz K, Nordberg A, Salmon E, Perani D, Kessler J, Mielke R, Halber M,
Jelic V, Almkvist O, Collette F, Alberoni M, Kennedy A, Hasselbalch S, Fazio F, Heiss WD: Impairment of neocortical metabolism predicts progression in Alzheimer's disease. Dement Geriatr Cogn Disord 1999, 10:494-504.

77. Silverman DHS, Small GW, Chang CY, Lu CS, Kung De Aburto MA, Chen W, Czernin J, Rapoport SI, Pietrini P, Alexander GE, Schapiro MB, Jagust WJ, Hoffman JM, Welsh-Bohmer KA, Alavi A, Clark CM, Salmon E, de Leon MJ, Mielke R, Cummings JL, Kowell AP, Gambhir SS, Hoh CK, Phelps ME: Positron emission tomography in evaluation of dementia - regional brain metabolism and long-term outcome. JAMA 2001, 286:2120-2127.

78. Reiman EM, Caselli RJ, Yun LS, Chen K, Bandy D, Minoshima S, Thibodeau SN, Osborne D: Preclinical evidence of Alzheimer's disease in persons homozygous for the e4 allele for apolipoprotein E. N Eng/ J Med 1996, 334:752-758.

79. Kennedy AM, Frackowiak RSJ, Newman SK, Bloomfield PM, Seaward J, Roques P, Lewington G, Cunningham VJ, Rossor MN: Deficits in cerebral glucose metabolism demonstrated by positron emission tomography in individuals at risk of familial Alzheimer's disease. Neurosci Lett 1995, 186:17-20.

80. Ewers M, Insel P, Jagust WJ, Shaw L, Trojanowski JQ, Aisen P, Petersen RC, Schuff N, Weiner MW: CSF biomarker and PIB-PET-derived beta-amyloid signature predicts metabolic, gray matter, and cognitive changes in nondemented subjects. Cerebral Cortex 2012, 22:1993-2004

81. Langbaum JBS, Chen K, Lee W, Reschke C, Bandy D, Fleisher AS, Alexander GE, Foster NL, Weiner MW, Koeppe RA, Jagust WJ, Reiman EM: Categorical and correlational analyses of baseline fuorodeoxyglucose positron emission tomography images from the Alzheimer's Disease Neuroimaging Initiative (ADNI). Neurolmage 2009, 45:1107-1116.

82. Caselli RJ, Chen K, Lee W, Alexander GE, Reiman EM: Correlating cerebral hypometabolism with future memory decline in subsequent converters to amnestic pre-mild cognitive impairment. Arch Neurol 2008, 65:1231-1236.

83. Landau SM, Harvey D, Madison CM, Reiman EM, Foster NL, Aisen PS, Petersen RC, Shaw LM, Trojanowski JQ, Jack CR Jr, Weiner MW, Jagust WJ: Comparing predictors of conversion and decline in mild cognitive impairment. Neurology 2010, 75:230-238.

84. Landau SM, Harvey D, Madison CM, Koeppe RA, Reiman EM, Foster NL, Weiner MW, Jagust WJ: Associations between cognitive, functional, and FDG-PET measures of decline in AD and MCl. Neurobiol Aging 2011, 32:1207-1218

85. Caroli A, Frisonia GB; Alzheimer's Disease Neuroimaging Initiative: The dynamics of Alzheimer's disease biomarkers in the Alzheimer's Disease Neuroimaging Initiative cohort. Neurobio/ Aging 2010, 31:1263-1274

86. Yuan Y, Gu ZX, Wei WS: Fluorodeoxyglucose-positron-emission tomography, single-photon emission tomography, and structural MR imaging for prediction of rapid conversion to Alzheimer disease in patients with mild cognitive impairment: a meta-analysis. Am J Neuroradiol 2009, 30:404-410.

87. Mosconi L, Berti V, Glodzik L, Pupi A, De Santi S, de Leon MJ: Pre-clinical detection of Alzheimer's disease using FDG-PET, with or without amyloid imaging. J Alzheimers Dis 2010, 20:843-854.

88. Berti V, Osorio RS, Mosconi L, Li Y, De Santi S, de Leon MJ: Early detection of Alzheimer's disease with PET imaging. Neurodegen Dis 2010, 7:131-135.

89. During EH, Osorio RS, Elahi FM, Mosconi L, de Leon MJ: The concept of FDG-PET endophenotype in Alzheimer's disease. Neurol Sci 2011, 32:559-569.

90. Chen K, Langbaum JBS, Fleisher AS, Ayutyanont N, Reschke C, Lee W, Liu X, Bandy D, Alexander GE, Thompson PM, Foster NL, Harvey DJ, de Leon MJ, Koeppe RA, Jagust WJ, Weiner MW, Reiman EM: Twelve-month metabolic declines in probable Alzheimer's disease and amnestic mild cognitive impairment assessed using an empirically pre-defined statistical regionof-interest: findings from the Alzheimer's Disease Neuroimaging Initiative. Neurolmage 2010, 51:654-664.

91. Eckert T, Barnes A, Dhawan V, Frucht S, Gordon MF, Feigin AS, Eidelberg D: FDG PET in the differential diagnosis of parkinsonian disorders. Neurolmage 2005, 26:912-921

92. Poston KL, Eidelberg D: ${ }^{18} \mathrm{~F}$-Fluorodeoxyglucose PET in the evaluation of Parkinson disease. PET Clin 2010, 5:55-64

93. Minoshima S, Frey KS, Koeppe RA, Foster NL, Kuhl DE: A diagnostic approach in Alzheimer's disease using three-dimensional sterotactic surface projections of fluorine-18-FDG PET. J Nucl Med 1995, 36:1238-1248. 
94. Chen WP, Samuraki M, Yanase D, Shima K, Takeda N, Ono K, Yoshita M, Nishimura S, Yamada M, Matsunari I: Effect of sample size for normal database on diagnostic performance of brain FDG PET for the detection of Alzheimer's disease using automated image analysis. Nucl Med Commun 2008, 29:270-276.

95. Ng S, Villemagne VL, Berlangieri S, Lee ST, Cherk M, Gong SJ, Ackermann U, Saunder T, Tochon-Danguy H, Jones G, Smith C, O'Keefe G, Masters CL, Rowe $\mathrm{CC}$ : Visual assessment versus quantitative assessment of ${ }^{11} \mathrm{C}-\mathrm{PIB}$ PET and ${ }^{18}$ F-FDG PET for detection of Alzheimer's disease. J Nucl Med 2007 48:547-552.

96. Coleman RE: Positron emission tomography diagnosis of Alzheimer's disease. Neuroimaging Clin N Am 2005, 15:837-846.

97. KlunkWE, Engler $\mathrm{H}$, Nordberg A, Wang Y, Blomqvist G, Holt DP, Bergström M Savitcheva I, Huang GF, Estrada S, Ausén B, Debnath ML, Barletta J, Price JC, Sandell J, Lopresti BJ, Wall A, Koivisto P, Antoni G, Mathis CA, Långström B: Imaging brain amyloid in Alzheimer's disease with Pittsburgh CompoundB. Ann Neurol 2004, 55:306-319.

98. Rowe C, Pejoska S, Mulligan RS, Jones G, Chan G, Svensson S, Cselényi Z, Masters C, Villemagne V: Head-to-head comparison of 11C-PIB and 18F-AZD4694 for beta-amyloid imaging in aging and dementia [abstract 01-04-04]. Alzheimer's Association International Conference Abstracts; July 14-19 2012; Vancouver, Canada.

99. Clark CM, Pontecorvo MJ, Beach TG, Bedell BJ, Coleman RE, Doraiswamy PM, Fleisher AS, Reiman EM, Sabbagh MN, Sadowsky CH, Schneider JA, Arora A, Carpenter AP, Flitter ML, Joshi AD, Krautkramer MJ, Lu M, Mintun MA, Skovronsky DM: Cerebral PET with florbetapir compared with neuropathology at autopsy for detection of neuritic amyloid- $\beta$ plaques: a prospective cohort study. Lancet Neurol 2012, 11:669-678.

100. Pike KE, Savage G, Villemagne VL, Ng S, Moss SA, Maruff P, Mathis CA, Klunk WE, Masters CL, Rowe CC: Beta-Amyloid imaging and memory in nondemented individuals: evidence for preclinical Alzheimer's disease. Brain 2007, 130:2837-2844.

101. Pontecorvo MJ, Mintun MA: PET amyloid imaging as a tool for early diagnosis and identifying patients at risk for progression to Alzheimer's disease. Alzheimers Res Ther 2011, 3:11.
102. Okello A, Koivunen J, Edison P, Archer HA, Turkheimer FE, Någren K, Bullock $R$, Walker Z, Kennedy A, Fox NC, Rossor MN, Rinne JO, Brooks DJ: Conversion of amyloid positive and negative $\mathrm{MCl}$ to $\mathrm{AD}$ over 3 years: an ${ }^{11} \mathrm{C}$-PIB PET study. Neurology 2009, 73:754-760.

103. Rowe CC, Ellis KA, Rimajova M, Bourgeat P, Pike KE, Jones G, Fripp J, TochonDanguy H, Morandeau L, O'Keefe G, Price R, Raniga P, Robins P, Acosta O, Lenzo N, Szoeke C, Salvado O, Head R, Martins R, Masters CL, Ames D, Villemagne $\mathrm{VL}$ : Amyloid imaging results from the Australian Imaging, Biomarkers and Lifestyle (AIBL) study of aging. Neurobiol Aging 2010, 31:1275-1283.

104. Rabinovici GD, Rosen HJ, Alkalay A, Kornak J, Furst AJ, Agarwal N, Mormino EC, O'Neil JP, Janabi M, Karydas A, Growdon ME, Jang JY, Huang EJ, Dearmond SJ, Trojanowski JQ, Grinberg LT, Gorno-Tempini ML, Seeley WW, Miller BL, Jagust WJ: Amyloid versus FDG PET in the differential diagnosis of AD and FTLD. Neurology 2011, 77:2034-2042.

105. Laforce RJr, Rabinovici GD: Amyloid imaging in the differential diagnosis of dementia: review and potential clinical applications. Alzheimers Res Ther 2011, 3:31.

106. Wolk, DA, Price, JC, Madeira, Saxton JA, Snitz BE, Lopez OL, Mathis CA, Klunk WE, DeKosky ST: Amyloid imaging in dementias with atypical presentation. Alzheimers Dement 2012, 8:1-10.

107. Johnson KA, Minoshima S, Bohnen NI, Donohoe KJ, Foster NL, Herscovitch P, Karlawish JH, Rowe CC, Carrillo MC, Hartley DM, Hedrick S, Pappas V, Thies WH: Appropriate use criteria for amyloid PET: a report of the Amyloid Imaging Task Force, the Society of Nuclear Medicine and Molecular Imaging, and the Alzheimer's Association. Alzheimers Dement 2013, 9:1-15.

doi:10.1186/alzrt199

Cite this article as: Soucy JP, et al.: Clinical applications of neuroimaging in patients with Alzheimer's disease: a review from the Fourth Canadian Consensus Conference on the Diagnosis and Treatment of Dementia 2012. Alzheimer's Research \& Therapy 2013, 5(Suppl 1):S3. 